\title{
RESEARCH
}

Open Access

\section{Bladder preservation approach versus radical cystectomy for high-grade non-muscle-invasive bladder cancer: a meta-analysis of cohort studies}

\author{
Pei-lin Shen ${ }^{1,2}$, Ming-en lin ${ }^{1}$, Ying-kai Hong ${ }^{1}$ and Xue-jun $\mathrm{He}^{1^{*}}$ (1)
}

\begin{abstract}
Background: High-grade non-muscle-invasive bladder cancer is superficial; nonetheless, it is an aggressive cancer. Proper management strategy selection following transurethral resection between bladder preservation (BP) and radical cystectomy $(\mathrm{RC})$ could result in delayed or excessive treatment. Hence, selecting the optimal treatment modality remains controversial to date.

Methods: We searched MEDLINE, The Cochrane Library, EMBASE, China National Knowledge Infrastructure, and Wanfang database through 12 April 2018. Quality and publication bias were assessed using the Newcastle-Ottawa Scale and Begg's/Egger's test. We collected 2-year, 5-year, 10-year, and 15-year survival rate and hazard ratio (HR) for overall survival (OS), cancer-specific survival (CSS), and progression-free survival (PFS). Using the Review Manager 5.2 software, we used the odds ratio (OR) of specific years and HR for meta-analysis. Subgroup analysis was performed by the original tumor state, radical cystectomy timing, bladder preservation modality, and age.

Results: In total, 11 cohorts with 1735 patients were selected for the meta-analysis. All OR of OS supported BP as a better treatment option; however, all OR of PFS had no significant differences. As for CSS, only the 15-year OR reflected a statistical significance preferring RC. Subgroup analysis showed that BP is more appropriate for patients older than 65 and G3 tumor. Limited data demonstrated that late RC (> 3 months) is more effective compared to early RC ( $<3$ months) and intravesical Bacillus Calmette-Guerin was not statistically different from that of RC. The mixed BP modalities were significantly better compared to RC in OS and worse in CSS, with both having a very low evidence strength.
\end{abstract}

Conclusions: BP is a superior treatment modality compare to RC, especially for older patients and T1G3 or lower grade tumors. However, the superior BP modality was unclear. Conversely, RC could be a better option for younger patients. More specifically, late RC may be more beneficial but had a very-low-level of evidence. Quality of life should be considered equal to survival outcome; hence, post-treatment follow-up needs to be performed. Prospective randomized studies should be performed to overcome the limitations of this metaanalysis study.

Registration: Registration ID is CRD42018093491.

Keywords: Bladder preservation, High-grade non-muscle-invasive bladder cancer, Radical cystectomy, Meta-analysis

\footnotetext{
* Correspondence: sdfyurology@126.com

1Department of Urology, The First Affiliated Hospital of Shantou University

Medical College, No. 57, Changping Road, Jinping District, Shantou,

Guangdong, China

Full list of author information is available at the end of the article
}

(c) The Author(s). 2018 Open Access This article is distributed under the terms of the Creative Commons Attribution 4.0 International License (http://creativecommons.org/licenses/by/4.0/), which permits unrestricted use, distribution, and reproduction in any medium, provided you give appropriate credit to the original author(s) and the source, provide a link to the Creative Commons license, and indicate if changes were made. The Creative Commons Public Domain Dedication waiver (http://creativecommons.org/publicdomain/zero/1.0/) applies to the data made available in this article, unless otherwise stated. 


\section{Background}

Bladder cancer (BC) has a high morbidity in patients worldwide. As the 9th most commonly diagnosed cancer and the 13th most common cause of death worldwide, BC caused 188,000 deaths in 2015 worldwide [1, 2].

Among the 81,190 estimated newly diagnosed BC in the US in 2018, nearly $75 \%$ were non-muscle-invasive bladder cancer (NMIBC). NMIBC is defined as a superficial neoplasia confined to the mucosa, (including Ta which is a noninvasive papillary carcinoma and carcinoma in situ (CIS) which is flat and non-papillary) or lamina propria (T1) based on the American Joint Committee on Cancer (AJCC) staging system, also known as the tumor node metastases (TNM) classification [3-5]. Histologically, BC is generally graded using the 1973 World Health Organization (WHO) classification system or the 2004 revision. The 1973 version comprises grade 1 to 3 and is based on the degree of cellular anaplasia compatible for the diagnosis of malignancy. Grade 1 (G1) applies to tumors having the least degree, grade 3 (G3) applies to tumors having the most severe degree, and grade 2 (G2) lies in between. The 2004 revision categorizes tumors into "low-grade (LG)" or "high-grade (HG)" depending on the neoplasm of the urothelium lining papillary fronds. This may show either an orderly appearance or with easily recognizable variations in architecture and cytologic features or a predominant pattern of disorder with moderate-to-marked architectural and cytologic atypia [6,7]. Both grading systems have confirmed prognostic value and have been accepted widely. However, which one is more clinically significant remains controversial [8-10]. In NMIBC, high-grade non-muscle-invasive bladder cancer (HGNMIBC) has the highest risk due to its aggressive clinical, biologic, and histopathologic characteristics [11, 12]. A 15-year study demonstrated that high-grade $\mathrm{T} 1$ bladder cancer had a $50 \%$ progression rate and had a mortality of $30 \%$ during patient follow-up [13]. Hence, the management strategy for HGNMIBC is an unmet clinical need.

Regarding bladder preservation (BP), intravesical Bacillus Calmette-Guerin (BCG) following transurethral resection (TUR) has been the gold standard for over 40 years and has been demonstrated to decrease recurrence rates, progression rates, and mortality in high-risk NMIBC patients [14-16]. However, several studies have reported that 23 to $74 \%$ high-grade $\mathrm{T} 1$ tumor recurred and more than $50 \%$ progressed after receiving intravesical BCG therapy [17-20]. The side-effects of BCG are common and can be severe; hence, new bladder preservation approaches for HGNMIBC should aim to provide better quality of life (QoL). However, clinical data on the different kinds of intravesical instillation, chemotherapy, radiotherapy, device assisted therapy, and electromotive drug administration is limited [21]. In addition, BP may cause inadequate treatment due to the delay of radical cystectomy (RC). About one third of patients treated with intravesical BCG still undergo RC during the treatment procedure [22]. Delay in RC may increase the risk of lymph node metastases and even bladder cancerspecific mortality [23, 24]. Thus, timely RC has to be performed during HGNMIBC treatment.

As HGNMIBC has a risk of recurrence and progression, $\mathrm{RC}$ has become a popular therapeutic strategy [25, 26]. There were multiple studies demonstrating that $\mathrm{RC}$ is the preferred treatment option due to better survival rates [27-29]. However, there is a consensus that RC and intravesical BCG shares the same curative effect and several studies have demonstrated that $\mathrm{RC}$ is therapeutically excessive [30]. The RC procedure includes surgically removing the whole bladder along with adjacent organs and reconstructing the urinary drainage, which could cause severe complications and even death. Several studies have reported that many patients suffered from different short-term complications which require more than 6 months for the QoL to normalize to preoperative levels [31]. Because survival and QoL outcomes remain uncertain, the impact of RC still needs to be explored further.

Major associations share similar treatment opinions for HGNMIBC. American Urological Association (AUA) guidelines [32] and European Association of Urology (EAU) guidelines [33] strongly recommends 6 weeks of BCG intravesical instillation for high-risk NMIBC and a maintenance schedule of up to 3 years. The National Comprehensive Cancer Network (NCCN) guidelines [34] also regard BP as the first line treatment option for the management of high-grade tumors. Specifically, observation and intravesical instillation (BCG and chemotherapeutics) should be selected for HG cTa patients whereas BCG is the only recommended BP modality for $\mathrm{HG}$ cT1 patients. As for $\mathrm{RC}, \mathrm{EAU}$, and $\mathrm{NCCN}$, their guidelines recommend that immediate or early (within 3 months of diagnosis) RC should be considered as an option worth discussing with a low grade of evidence. More specifically, AUA guidelines for grade $C$ suggest after a single course of BCG, RC should be offered for high-grade T1 patients who are fit for surgery and a second course of induction should be considered for persistent or recurrent high-grade Ta or CIS patients. However, NMIBC could be a mixture of CIS, Ta, and $\mathrm{T} 1$ instead of containing only one single grade of tumor. Although consensuses exists among the three guidelines, questions regarding $\mathrm{BP}$ selection, necessity and timing of $\mathrm{RC}$, and the selection of optimal treatment strategies between BP and RC still remain controversial [35, 36].

To help determine the optimal treatment modality, we performed a meta-analysis of BP versus $\mathrm{RC}$ for patients 
with HGNMIBC. The survival outcomes included overall survival (OS), cancer-specific survival (CSS), and progression-free survival (PFS).

\section{Methods}

\section{Registration information}

This meta-analysis is registered on PROSPERO (https:// www.crd.york.ac.uk/PROSPERO). The registration ID is CRD42018093491.

\section{Eligibility criteria}

Eligible studies met the following criteria: (1) The subject of the study were patients suffering from HGNMIBC (including "grade 3" under the 1973 WHO classification and "high-grade" under the 2004 WHO classification). All 1973 WHO G3 tumors are assigned to the $2004 \mathrm{WHO}$ high-grade carcinoma category while revising [37]. (2) Studies focusing on or containing the comparison between radical cystectomy and bladder preservation approach (observation, intravesical BCG, and/or any other kind of intravesical instillation) following TUR. A delayed radical cystectomy was performed if bladder preservation approach failed or the side-effects were intolerable. (3) The data of survival outcomes (OS, CSS, or PFS) were available.

Studies were excluded based on the following criteria: (1) Studies including patients with an original state of BCG refractory, resistance, or failure. (2) The key outcomes were not available. (3) Not intervention research such as review, letter, viewpoint, or case reports. (4) The sample size was less than 20 patients in total or 10 patients in BP/RC group.

\section{Search strategy}

We performed an internet search for relevant studies from The Cochrane Library, MEDLINE, EMBASE, CNKI (China National Knowledge Infrastructure), and Wanfang database through 12 April 2018. The search strategy was to combine MeSH terms (in MEDLINE and The Cochrane Library) or Emtree terms (in EMBASE) with free words from three English medical databases. As in CNKI and Wanfang database, we searched relative terms as Subject, Keyword, Title, and Abstract, and the explored field was restricted in Medicine and Health. Terms relating to or describing high-grade bladder cancer, cystectomy, and bladder preservation approach (including observation, BCG, intravesical instillation, bladder preservation) were used. There was no filter used for randomized controlled trials or cohort studies and no language restriction was applied. The search strategy for MEDLINE is demonstrated in Fig. 1. The full-text of all published studies including meeting abstracts that met the eligibility criteria were collected. No attempt was made to contact the authors for obtaining or confirming published data.

\section{Quality assessment}

All eligible studies were cohort studies, and the Newcastle-Ottawa Scale (NOS) was used for quality assessment [38]. The scale contained three categories: Selection, Comparability, and Outcome. Each numbered item within the Selection and Outcome were awarded one star. As for the Comparability group, a maximum of two stars were assigned. After the assessment, a total score range from 0 to 9 stars was calculated for every study. Study bias was scaled as high risk of bias (0-3 stars), middle risk of bias (4-6 stars), and low risk of bias (7-9 stars) and represented inferior quality, medium quality, and superior quality respectively.

STATA 12.0 software was used for publication bias assessment. Each comparison was assessed using Egger's test except for those containing only two studies where the Begg's test was used. $P>0.05$ was considered to have no publication bias.

\section{Data collection process}

Data was extracted from each article and included information on country, study interval, original tumor state, radical cystectomy timing, bladder preservation modality, gender composition, study size, age, median followup time, and type of outcomes. As for multiple articles by the same author, the latest article was selected for inclusion. Table 2 describes the characteristics of the included studies. 


\section{Synthesis of results}

From the selected studies, we collected 2-year, 5-year, 10 -year, and 15-year survival rate and hazard ratio (HR) of each outcome. If there was no direct data provided in the publication but a Kaplan-Meier survival curve was present, we extracted information from the curve using the Digitizer 4.1 software and then mathematically calculated the HR and survival rate. Using Review Manager 5.2 software, we used HR and odds ratio (OR) for meta-analysis and subgroup analysis was performed using the original tumor state, radical cystectomy timing, bladder preservation modality, and age. $A p$ value less than 0.05 of a pooled HR or OR was considered statistically significant.

Heterogeneity between the studies in effect measures was assessed using the $I^{2}$ statistic. An $I^{2}$ value greater than $50 \%$ was indicative of substantial heterogeneity and hence used the random effect model for synthesis. A fix effect model was used for synthesis if $I^{2}$ value was less than $50 \%$.

\section{Results}

\section{Study selection}

A total of 2947 articles (633 from MEDLINE, 1045 from EMBASE, 69 from the Cochrane Library, 572 from Wanfang database, and 628 from $\mathrm{CNKI}$ ) were assembled from all databases mentioned above. After removing duplicates, 2106 articles remained. By screening the titles and abstracts, 2056 articles were excluded with 50 articles meeting the inclusion criteria or unlikely to be rejected. After a full-text review, 23 articles including reviews, letters, protocols, viewpoints, editorials, comments, and case reports were excluded. Ten studies lacking key outcomes and two with sample size issues (one having 10 patients in total and one having only 7 patients in the RC group) were also excluded. When 2 articles were present from the same author, we chose the latest one for inclusion. Finally, there were 13 studies left, together with 2 studies selected from the references of relative articles. In all, a total of 15 studies were included for further quality assessment. After evaluating each study using the NOS scoring standard, 4 studies were excluded for middle risk of bias. In the end, 11 studies with superior quality were considered eligible for analysis (Table 1). The flow diagram of study selection is shown in Fig. 2.

\section{Study characteristics}

From Table 2, the comparison between BP and RC initiated from 2001 worldwide. A total of 1735 patients were selected for analysis. There are 7 studies that used the 1973 WHO grading system [27, 29, 39-43] while 4 used the 2004 revision [28, 44-46]. BP modality mentioned in the included studies were mostly intravesical therapy including BCG, epirubicin, mitomycin, and hydroxycamptothecine, and 2 studies even included observation as a BP strategy $[44,46]$. Several studies did not describe the BP modality specifically; however, the majority of the studies selected intravesical BCG as the BP strategy including 7 of them that used BCG only [27, 29, 39-42, 45]. Patients of 6 cohorts received RC within 3 months [27, 29, 39, 41, 44, 46] and 2 other cohorts had surgery with a median time of 4 months [28] and 16 months [42]. Summarizing the eligible data, males had the advantage in gender composition in all studies with a ratio of 1.4-7.2:1. The average patient age in all the cohorts was older than 60 . In the majority of the studies, the average age of the BP groups was older compared to the RC groups; however, no statistical significance was detected. The median follow-up time ranged from 38.4 months to 99.6 months. Extracted outcomes were HR and survival rate of specific years

Table 1 Newcastle-Ottawa Scale (NOS) score for included studies

\begin{tabular}{|c|c|c|c|c|c|c|c|c|c|c|c|}
\hline \multirow[t]{2}{*}{ Study } & \multirow[t]{2}{*}{ Year } & \multicolumn{4}{|l|}{ Selection } & \multicolumn{2}{|c|}{ Comparability } & \multicolumn{3}{|l|}{ Outcome } & \multirow[t]{2}{*}{ Scale } \\
\hline & & Exposed & $\begin{array}{l}\text { Non- } \\
\text { exposed }\end{array}$ & $\begin{array}{l}\text { Ascertainment } \\
\text { of exposure }\end{array}$ & $\begin{array}{l}\text { Start without } \\
\text { outcome present }\end{array}$ & $\begin{array}{l}\text { Major } \\
\text { factor }\end{array}$ & $\begin{array}{l}\text { Addition } \\
\text { factor }\end{array}$ & $\begin{array}{l}\text { Outcome } \\
\text { assessment }\end{array}$ & $\begin{array}{l}\text { Follow-up } \\
\text { length }\end{array}$ & $\begin{array}{l}\text { Adequacy } \\
\text { of outcome }\end{array}$ & \\
\hline Badalato & 2012 & मे & मे & मे & मे & मे & मे & मे & मे & & 8 \\
\hline De Berardinis & 2011 & मे & मे & मे & मे & मे & मे & मे & मै & & 8 \\
\hline Denzinger & 2008 & मे & मे & मे & मे & मे & मे & मे & मे & & 8 \\
\hline Hautmann & 2009 & मे & मे & मे & मे & & मे & मे & & & 7 \\
\hline Jager & 2011 & & น & मे & मे & मे & मे & मे & म & मे & 9 \\
\hline $\mathrm{Li}$ & 2011 & 4 & मे & मे & मे & मे & मै & मे & मे & & 8 \\
\hline Patard & 2001 & & मे & मे & मे & & मे & मे & tै & & 7 \\
\hline Spaliviero & 2014 & मे & मे & मे & मे & मे & मे & मे & & & 7 \\
\hline Sun & 2008 & मे & मे & मे & मे & मे & मे & मे & tै & & 8 \\
\hline Thalmann & 2004 & मे & मे & मे & मे & मे & मे & मे & मे & & 8 \\
\hline Wong & 2009 & मे & मे & मे & मे & मे & & मे & मे & & 7 \\
\hline
\end{tabular}




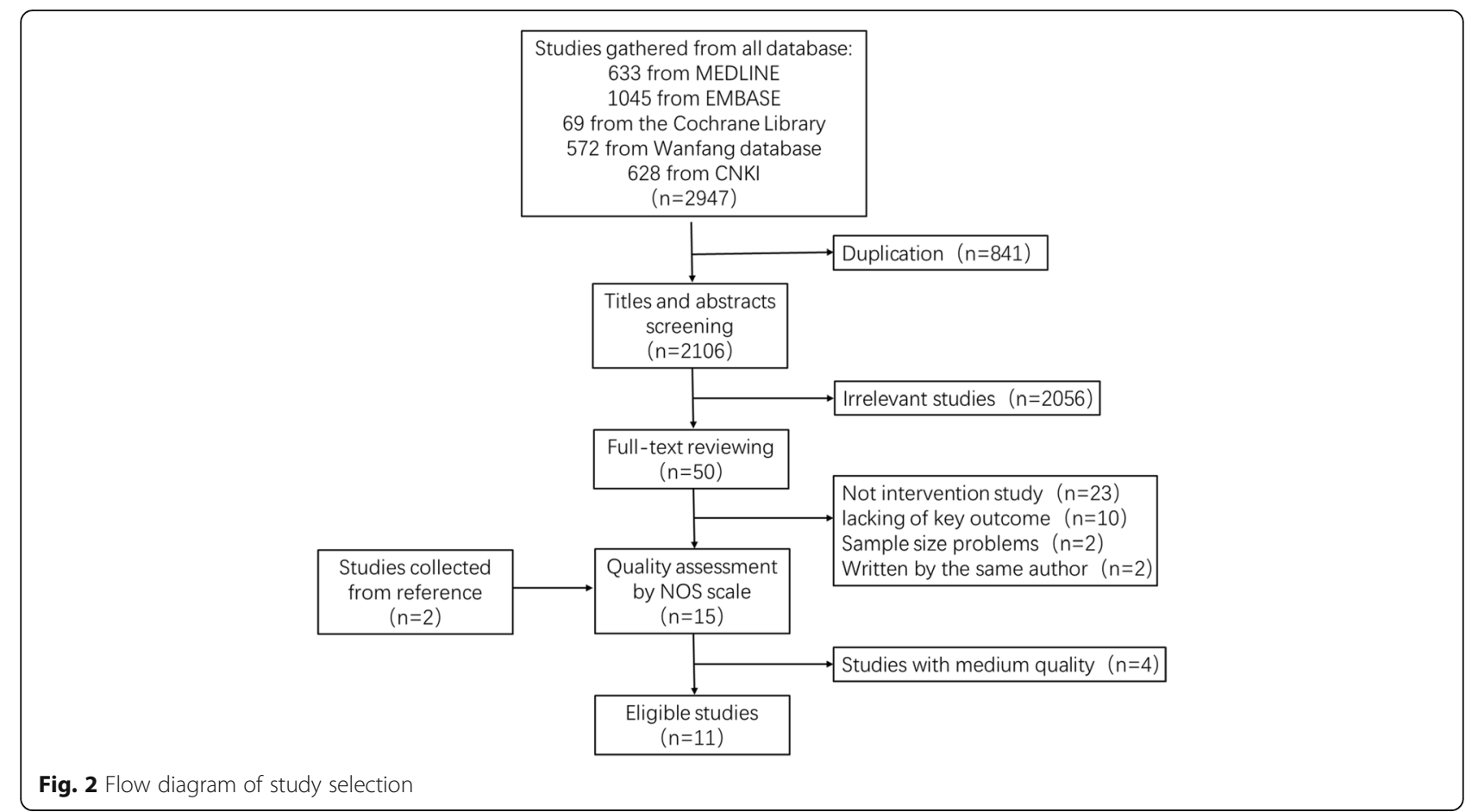

including OS from 6 studies, CSS from 10 studies, and PFS from 3 studies.

\section{Comparison of overall survival of bladder preservation versus radical cystectomy}

Six studies were selected for our OS meta-analysis. Only 2 articles had retrievable HR data and the combined HR, and the 95\% confidence interval (CI) was $0.47(0.25-$ $0.89)$ with a statistical significance $(P=0.02)$. Heterogeneity was considered acceptable with an $I^{2}=37 \%$ (Fig. 3a, Table 3). No subgroup analysis was performed due to data unavailability.

With regards to the 2-year, 5-year, and 10-year OS, the pooled OR were $0.25(95 \% \mathrm{CI}=0.08-0.74, P=0.01$, $\left.I^{2}=0 \%\right), 0.63\left(95 \% \mathrm{CI}=0.43-0.92, P=0.02, I^{2}=0 \%\right)$, and $0.62\left(95 \% \mathrm{CI}=0.43-0.88, P=0.007, I^{2}=0 \%\right)$, respectively (Fig. 4, Table 4). Only one article provided OR of 15-year OS which was $0.35(95 \% \mathrm{CI}=0.13-0.95$, $P=0.04)$. The subgroup analysis was performed for only the 2-year, 5-year, and 10-year OS because of data deficiency for the 15-year OS and all indicated BP as a better treatment option for patients older than 65 years old $(P=0.01,0.009$, and 0.004 respectively). In the 5 -year OS, the same result as mentioned before regarding BP was found for the G3 group of subgroup analysis for original tumor state $(P=0.01)$ and mix group of subgroup analysis for bladder preservation modality $(P=0.02)$. Subgroup analysis for all $\mathrm{RC}$ timing groups was not carried out. No significant heterogeneity was found for all subgroups (Table 4).

\section{Comparison of cancer-specific survival of bladder} preservation versus radical cystectomy

Data for CSS was extractable from 9 studies and the combined HR was $0.91(95 \% \mathrm{CI}=0.44-1.87, P=0.79)$ synthesizing from 6 of them having significant heterogeneity $\left(I^{2}=83 \%\right)$ (Fig. $3 \mathrm{~b}$, Table 3$)$. All subgroups presented insignificant differences between the two management strategies and significant heterogeneities expect for patients younger than 65 years old $(P=0.05$, $I^{2}=0 \%$ ), and receiving $\mathrm{RC}$ for more than 3 months from diagnosis was only present in one single study $(P=0.02)$ (Table 3).

Insignificant differences were observed from the pooled OR and 95\%CI for 2-year, 5-year, and 10-year CSS which were $0.78\left(0.33-1.81, P=0.56, I^{2}=73 \%\right), 0.78(0.44-1.38$, $\left.P=0.4, I^{2}=75 \%\right)$, and $1.22\left(0.59-2.52, P=0.6, I^{2}=80 \%\right)$, respectively (Fig. 5, Table 5). The analysis of the 15-year CSS reflected significant differences with an $\mathrm{OR}=2.19$ (95\%CI $=1.21-3.95, P=0.009)$; however, the heterogeneity was significant $\left(I^{2}=55 \%\right)$, and subgroup analysis was unable to be performed. All subgroup analysis failed to confirm any significant differences for 2-year CSS expect for a subgroup with only one study in favor of RC surgery after more than 3 months from diagnosis versus BP $(P=0.02)$. For the 10-year CSS, a statistical significance suggesting RC performed more than 3 months from diagnosis could reduce $\mathrm{BC}$ mortality compared to BP was observed and was the same study as RC timing subgroup analysis in HR and 2 -year $\operatorname{OS}(P=0.002)$. As for the subgroup analysis of original tumor states and bladder preservation modality in 


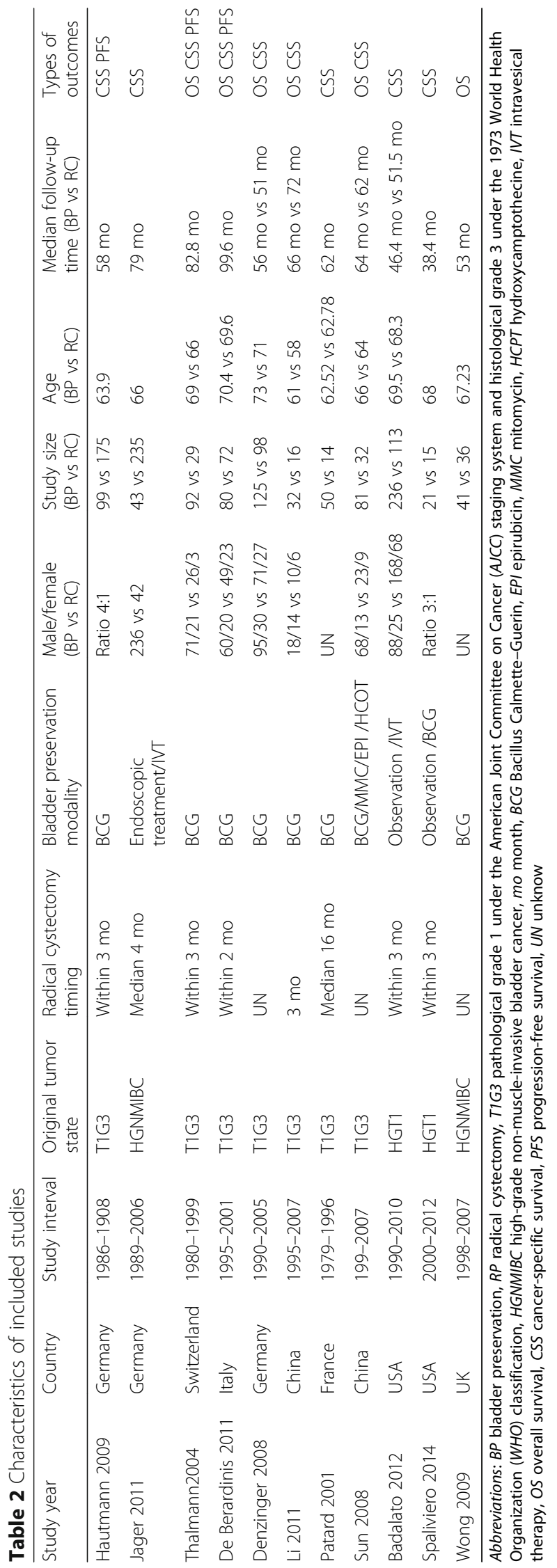




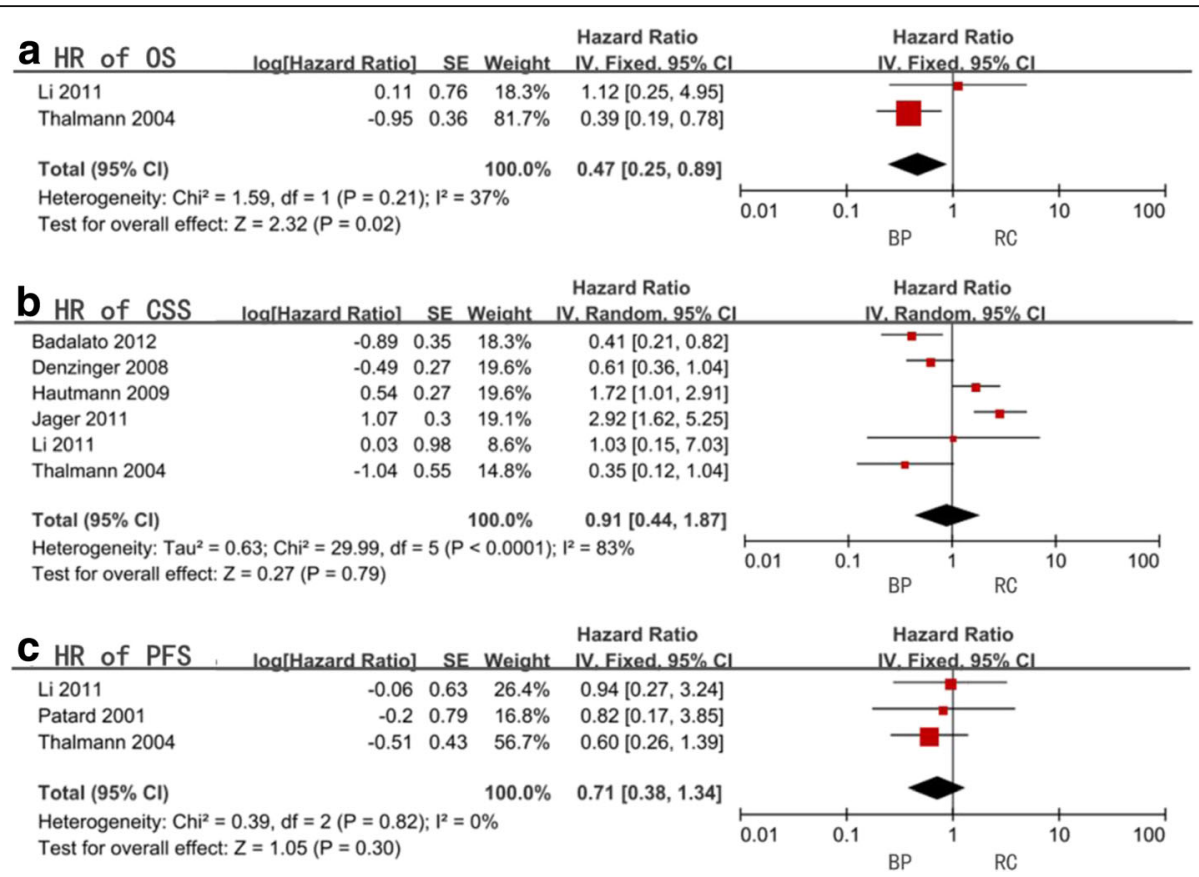

Fig. 3 Forest plots of hazard ratio (HR)

10-year CSS, HG group $(P=0.002)$ and mix group $(P=$ 0.002 ) shared the same statistical significance preferring RC as a superior treatment. Unlike OS, no significant difference was observed with age (Table 5).

\section{Comparison of progression-free survival of bladder preservation versus radical cystectomy}

Four studies provided data for PFS and three of them had data of HR. No statistical significance was reported between the two treatment modalities $(\mathrm{HR}=$ $0.71,95 \% \mathrm{CI}=0.38-1.34, P=0.3)$ with insignificant heterogeneity $\left(I^{2}=0 \%\right.$ ) (Fig. 3c, Table 3$)$. The subgroup analysis was conducted for radical cystectomy timing and age but no significant difference was found (Table 3).

For the 2-year, 5-year, 10-year, and 15-year PFS, our meta-analysis showed no statistical significance and the pooled OR and $95 \% \mathrm{CI}$ were $0.51(0.24-1.07, P=0.08)$,

Table 3 Meta-analysis of hazard ratio (HR)

\begin{tabular}{|c|c|c|c|c|c|}
\hline & Factors & & Study size & HR (95\%Cl, $P$ value) & $P^{2}(\%)$ \\
\hline$\overline{O S}$ & All included studies & & 2 & $0.47(0.25-0.89,0.02)$ & 37 \\
\hline \multirow[t]{9}{*}{ CSS } & All included studies & & 6 & $0.91(0.44-1.87,0.79)$ & 83 \\
\hline & \multirow[t]{2}{*}{ Original tumor state } & $H G$ & 2 & $1.10(0.16-7.53,0.92)$ & 94 \\
\hline & & G3 & 4 & $0.99(0.53-1.87,0.98)$ & 59 \\
\hline & \multirow[t]{2}{*}{ Radical cystectomy timing } & $>3$ months & 1 & $2.92(1.62-5.25,0.0004)$ & not available \\
\hline & & $<3$ months & 4 & $0.71(0.28-1.83,0.48)$ & 78 \\
\hline & \multirow[t]{2}{*}{ Bladder preservation modality } & BCG & 4 & $0.81(0.38-1.75,0.59)$ & 72 \\
\hline & & Mix & 2 & $1.10(0.16-7.53,0.92)$ & 94 \\
\hline & \multirow[t]{2}{*}{ Age } & $<65$ years old & 2 & $1.66(0.99-2.76,0.05)$ & 0 \\
\hline & & $>65$ years old & 4 & $0.74(0.28-1.98,0.55)$ & 88 \\
\hline \multirow[t]{5}{*}{ PFS } & All included studies & & 3 & $0.71(0.38-1.34,0.3)$ & 0 \\
\hline & \multirow[t]{2}{*}{ Radical cystectomy Timing } & $>3$ months & 1 & $0.82(0.17-3.85,0.8)$ & not available \\
\hline & & $<3$ months & 2 & $0.69(0.35-1.39,0.3)$ & 0 \\
\hline & \multirow[t]{2}{*}{ Age } & $<65$ years old & 2 & $0.89(0.34-2.34,0.82)$ & 0 \\
\hline & & $>65$ years old & 1 & $0.60(0.26-1.39,0.24)$ & not available \\
\hline
\end{tabular}




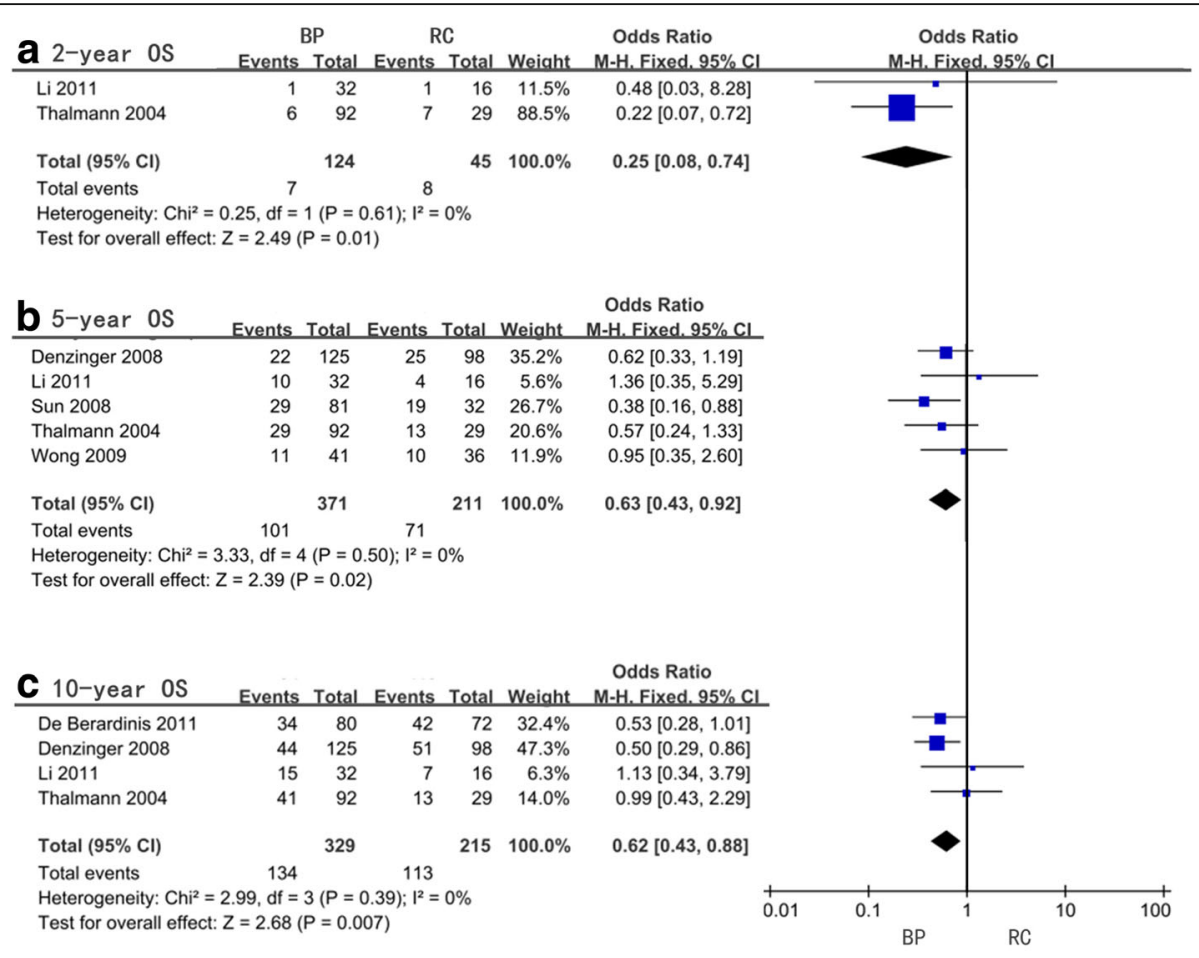

Fig. 4 Forest plots of odds ratio (OR) for overall survival (OS)

$1.17(0.75-1.82, P=0.49), 0.80(0.30-2.14, P=0.66)$, and 1.07 (0.08-13.68, $P=0.96$ ), respectively (Fig. 6, Table 6). With respect to 2-year PFS $\left(I^{2}=0 \%\right)$ and 5-year PFS $\left(I^{2}=46 \%\right)$, no significant heterogeneity was found while the 10 -year PFS $\left(I^{2}=54 \%\right)$ and 15 -year PFS $\left(I^{2}=91 \%\right)$ were significant. Limited subgroup analysis was performed and none of them showed any significant differences (Table 6).

\section{Publication bias}

No evidence for publication bias was present for OS $(P=1), \operatorname{CSS}(P=0.599)$, and PFS $(P=0.383)$ (Fig. 7$)$ as well as all the specific year groups. (Fig. 8).

\section{Discussion}

Intravesical BCG was first used as a treatment for superficial bladder cancer in 1976 [47]. Since then, this

Table 4 Meta-analysis of odds ratio (OR) for overall survival (OS)

\begin{tabular}{|c|c|c|c|c|c|}
\hline OS & Factors & & Study size & OR (95\%Cl, $P$ value) & $P^{2}(\%)$ \\
\hline \multirow[t]{3}{*}{$2-y r$} & All included studies & & 2 & $0.25(0.08-0.74,0.01)$ & 0 \\
\hline & Age & $<65$ years old & 1 & $0.48(0.03-8.28,0.62)$ & not available \\
\hline & & $>65$ years old & 1 & $0.22(0.07-0.72,0.01)$ & not available \\
\hline \multirow[t]{7}{*}{$5-y r$} & All included studies & & 5 & $0.63(0.43-0.92,0.02)$ & 0 \\
\hline & Original tumor state & $H G$ & 1 & $0.95(0.35-2.60,0.93)$ & not available \\
\hline & & G3 & 4 & $0.58(0.39-0.88,0.01)$ & 0 \\
\hline & Bladder preservation modality & $B C G$ & 4 & $0.71(0.46-1.10,0.13)$ & 0 \\
\hline & & Mix & 1 & $0.38(0.16-0.88,0.02)$ & not available \\
\hline & Age & $<65$ years old & 1 & $1.36(0.35-5.29,0.65)$ & not available \\
\hline & & $>65$ years old & 4 & $0.58(0.39-0.87,0.009)$ & 0 \\
\hline \multirow[t]{3}{*}{$10-y r$} & All included studies & & 4 & $0.62(0.43-0.88,0.007)$ & 0 \\
\hline & Age & $<65$ years old & 1 & $1.13(0.34-3.79,0.84)$ & not available \\
\hline & & $>65$ years old & 3 & $0.58(0.40-0.84,0.004)$ & 0 \\
\hline $15-y r$ & All included studies & & 1 & $0.35(0.13-0.95,0.04)$ & not available \\
\hline
\end{tabular}




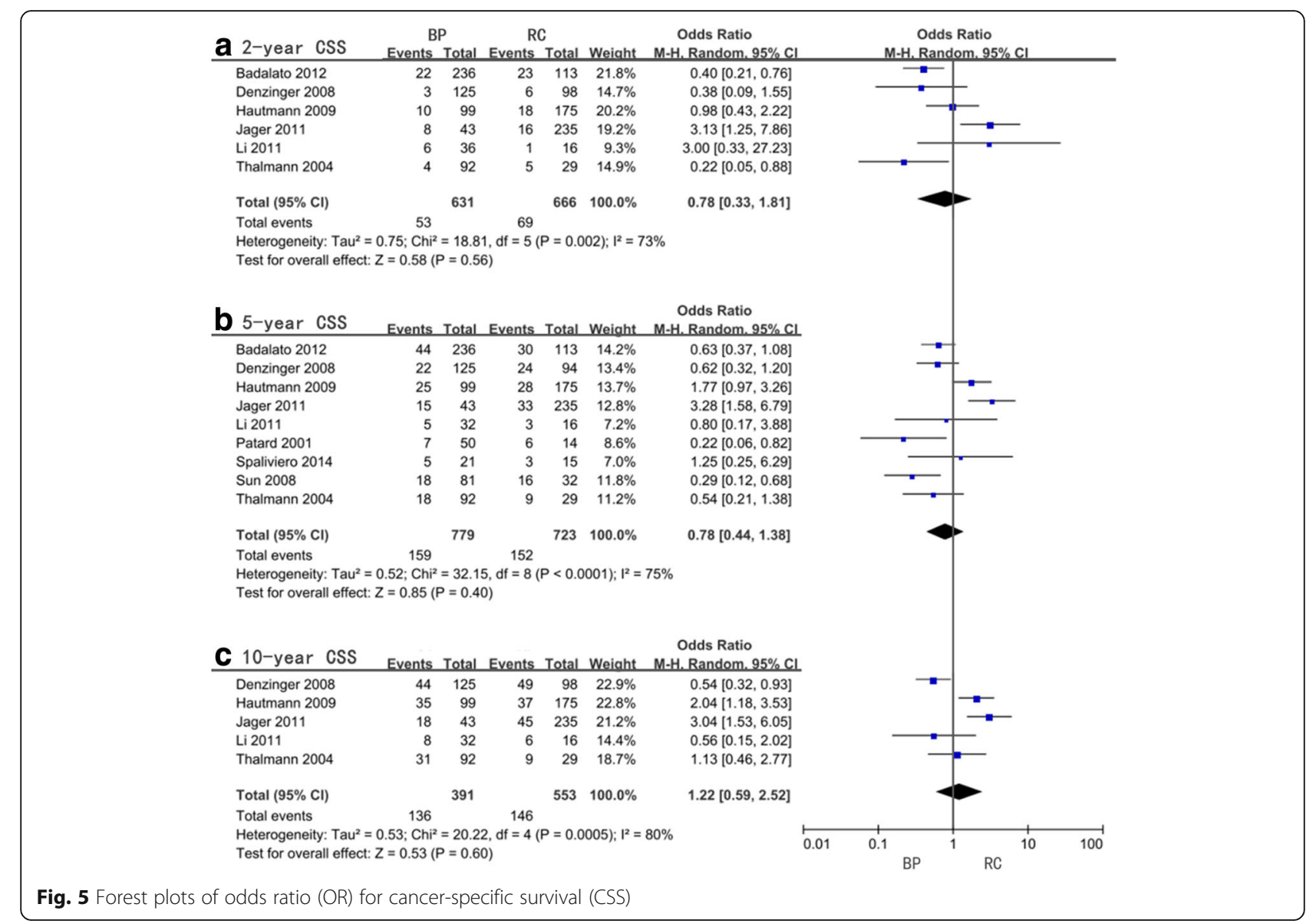

treatment has gradually become the gold standard and stood the test of time for decades. Nowadays, several new bladder preservation approaches have emerged to replace BCG by providing comparable therapeutic efficacy and better quality of life. However, with reference to HGNMIBC regarding high risk of recurrence, progression, and disease-specific death, radical cystectomy still cannot be ruled out during the treatment selection procedure.

In order to provide convincing therapeutic evidence, we performed this meta-analysis to compare $\mathrm{BP}$ and $\mathrm{RC}$ in HGNMIBC patients. HR was used to compare treatment modality risk through time. The 2-year, 5-year, 10-year, and 15-year OR were used to assess the short-term to long-term survival outcome.

Firstly, all OR and HR of OS reflected significant difference in favor of BP as recommend in AUA, EAU, and NCCN guidelines. As for the subgroup analysis, approximately all groups showed post-BP patients having better survival compared to post-RC patients except for RC patients younger than 65 years old in 5-year and 10-year OS where overall survival advantage versus BP was not statistically significant. However, only several subgroup analyses showed significant differences supporting BP including the G3 group (5-year OS) and >65-year-old group (5-year and 10-year OS). Hence, we concluded that BP was a more effective treatment modality for HGNMIBC especially for older patients and patients with G3 state tumors. The recommendation has been made that $\mathrm{BC}$ patients with failure of local therapy or progression should receive $\mathrm{BP}$ following delayed $\mathrm{RC}$ rather than immediate RC [48]. The superiority of mixed $\mathrm{BP}$ modality compared to RC for 5-year OS could indicate the inferiority of BCG, yet the strength of the evidence is very low. Regarding the original tumor state, the difference in mid-term overall survival may be affected only in T1 patients in the G3 group.

Unlike the OS analysis, the results of CSS failed to confirm any significant difference except for the 15-year CSS, which suggested RC was a better management option for long-term results. The different results between OS and CSS could be explained due to RC causing non-BC mortality. We observed that OR of CSS gradually increases over time. This result may indicate that the complication of surgery has a great impact and decreases over time. A previous long-term study reported $28 \%$ of early complications for RC and caused $2.5 \%$ of peri-operative deaths [35]. Including from what we 
Table 5 Meta-analysis of odds ratio (OR) for cancer-specific survival (CSS)

\begin{tabular}{|c|c|c|c|c|c|}
\hline$\overline{C S S}$ & Factors & & Study size & OR (95\%Cl, $P$ value $)$ & $P^{2}(\%)$ \\
\hline \multirow[t]{9}{*}{$2-y r$} & All included studies & & 6 & $0.78(0.33-1.81,0.56)$ & 73 \\
\hline & Original tumor state & $H G$ & 2 & $1.09(0.15-8.15,0.93)$ & 92 \\
\hline & & G3 & 4 & $0.63(0.25-1.60,0.33)$ & 48 \\
\hline & Radical cystectomy timing & $>3$ months & 1 & $3.13(1.25-7.86,0.02)$ & not available \\
\hline & & $<3$ months & 4 & $0.59(0.26-1.32,0.2)$ & 56 \\
\hline & Bladder preservation modality & $\mathrm{BCG}$ & 4 & $0.63(0.25-1.60,0.33)$ & 48 \\
\hline & & Mix & 2 & $1.09(0.15-8.15,0.93)$ & 92 \\
\hline & Age & $<65$ years old & 2 & $1.12(0.52-2.41,0.77)$ & 0 \\
\hline & & $>65$ years old & 4 & $0.60(0.18-1.98,0.4)$ & 82 \\
\hline \multirow[t]{9}{*}{$5-y r$} & All included studies & & 9 & $0.78(0.44-1.38,0.4)$ & 75 \\
\hline & Original tumor state & $H G$ & 3 & $1.37(0.40-4.67,0.62)$ & 84 \\
\hline & & G3 & 6 & $0.59(0.30-1.16,0.13)$ & 70 \\
\hline & Radical cystectomy timing & $>3$ months & 2 & $0.89(.06-2.87,0.93)$ & 92 \\
\hline & & $<3$ months & 5 & $0.91(0.52-1.58,0.73)$ & 49 \\
\hline & Bladder preservation modality & $\mathrm{BCG}$ & 5 & $0.70(0.35-1.41,0.32)$ & 65 \\
\hline & & Mix & 4 & $0.91(0.31-2.71,0.87)$ & 85 \\
\hline & Age & $<65$ years old & 3 & $0.74(0.19-2.83,0.66)$ & 76 \\
\hline & & $>65$ years old & 6 & $0.78(0.39-1.55,0.47)$ & 77 \\
\hline \multirow[t]{9}{*}{$10-y r$} & All included studies & & 5 & $1.22(0.59-2.52,0.6)$ & 80 \\
\hline & Original tumor state & $H G$ & 1 & $3.04(1.53-6.05,0.002)$ & not available \\
\hline & & G3 & 4 & $0.96(0.45-2.03,0.91)$ & 76 \\
\hline & Radical cystectomy timing & $>3$ months & 1 & $3.04(1.53-6.05,0.002)$ & not available \\
\hline & & $<3$ months & 3 & $1.51(0.97-2.34,0.07)$ & 48 \\
\hline & Bladder preservation modality & $\mathrm{BCG}$ & 4 & $0.96(0.45-2.03,0.91)$ & 76 \\
\hline & & Mix & 1 & $3.04(1.53-6.05,0.002)$ & not available \\
\hline & Age & $<65$ years old & 2 & $1.22(0.35-4.24,0.75)$ & 70 \\
\hline & & $>65$ years old & 3 & $1.22(0.41-3.65,0.73)$ & 87 \\
\hline $15-y r$ & All included studies & & 3 & $2.19(1.21-3.95,0.009)$ & 55 \\
\hline
\end{tabular}

observed from the OS results, $\mathrm{RC}$ may be a better treatment option for younger patients with better life expectancy, while BP is a better option for elderly patients [49]. The subgroup analysis of radical cystectomy timing showed that RC surgery performed after more than 3 months from diagnosis was a better treatment opinion compared to BP in the subgroup analysis of HR and OR (2-year and 10-year CSS) in the same single study. Therefore, these results may further prove the advantage of BP following a delayed RC. BCG was considered a better option compared to mix of BP modality, i.e., compared to RC separately in the 10-year CSS, which was opposite to the result of the 5-year OS; however, both had a low degree of evidence strength. But this paradoxical result could be explained by the non-cancer-specific death in RC as well. Although a metaanalysis reported that no statistical significance was found in survival outcome between BCG and MMC [50], recent randomized controlled studies have confirmed that BCG has a better recurrence prevention compared to epirubicin [51], epirubicin+interferon [52], or MMC [53]. Hence, BP modality selection is still complex and unclear. Hence, we may need to weigh the advantages and disadvantages of different BP before selection. Regarding original tumor state, RC showed a statistically significant better result for the 10 -year CSS in the HG group. This could be explained by CIS, as a confirmed risk factor that decreases survival rates in high-grade tumors [54]. Hence, a more aggressive treatment modality like $\mathrm{RC}$ may be more suitable but has to be confirmed in more studies.

Intravesical BCG and $\mathrm{RC}$ are considered progressionreducing modalities in separate studies for $\mathrm{BC}[55,56]$. When comparing the two treatment modalities, the HR and OS results in PFS showed no significant difference with all subgroup analysis having limited quantities due to lack of data. Hence, both BP and RC may have the same effect on preventing disease progression. 


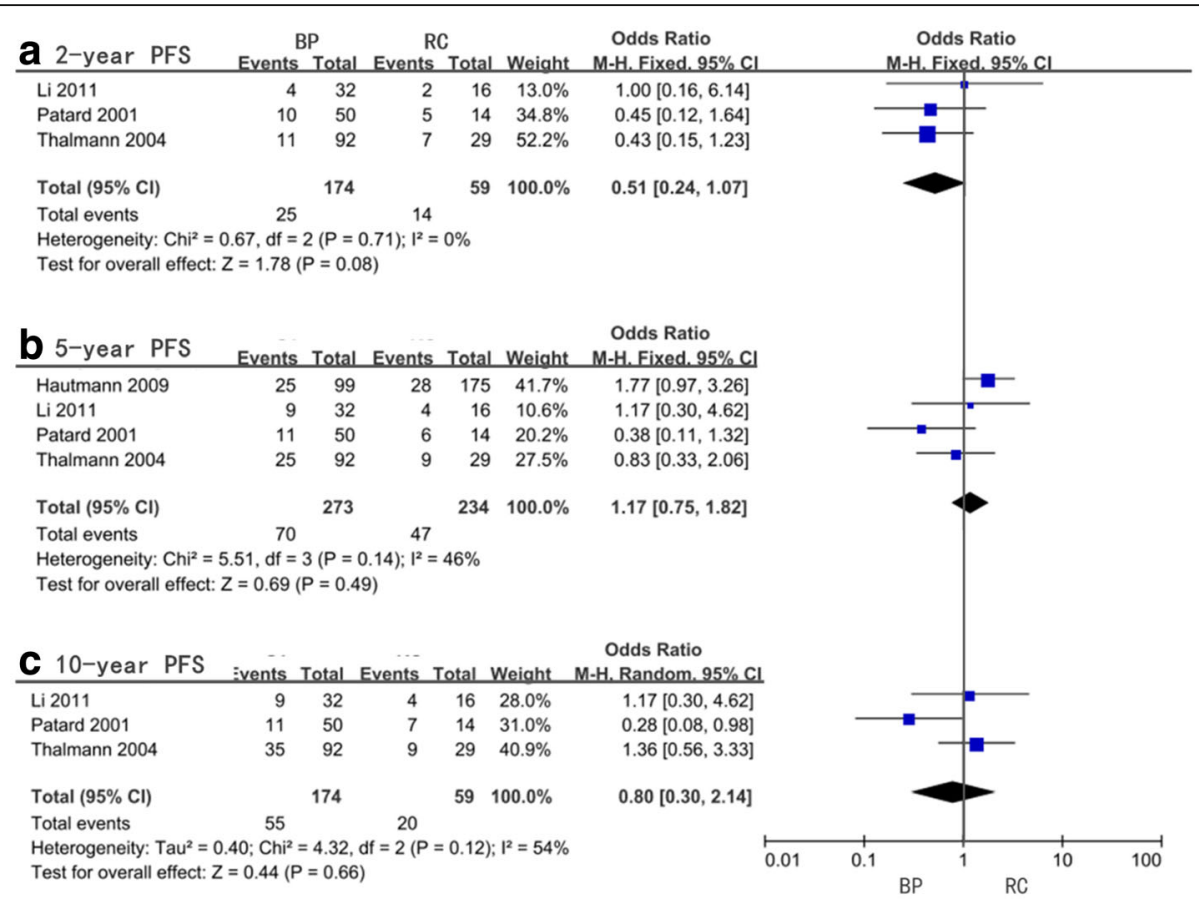

Fig. 6 Forest plots of odds ratio (OR) for progression-free survival (PFS)

In addition to survival outcome, quality of life was mostly affected by the side-effects and complications of treatment and is a crucial determinant for deciding a management modality. Body image and emotional and psychosocial stress are well-known psychosocial sideeffects of RC, and more than $80 \%$ of patients receiving $\mathrm{RC}$ complained of sexual dysfunction $[57,58]$. More importantly, severe complications such as fistulas often require surgical repair and sometimes could result in death $[59,60]$. As for BP, the side-effect of BCG are usually mild; however, less than $5 \%$ of patients can present with severe systemic complications and may even be life-threatening [61]. When choosing the optimal management for HGNMIBC, both survival outcome and QoL outcome need to be weighted according to patients' characteristics and life expectancy. In addition, the necessity of close follow-up is unarguable and recommended by AUA, EUA, and NCCN guidelines. Even for RC patients, strict long-term monitoring and continuous follow-up are indispensable for monitoring

Table 6 Meta-analysis of odds ratio (OR) for progression-free survival (PFS)

\begin{tabular}{|c|c|c|c|c|c|}
\hline PFS & Factors & & Study size & OR (95\%Cl, $P$ value) & $R^{2}(\%)$ \\
\hline \multirow[t]{3}{*}{$2-y r$} & All included studies & & 3 & $0.51(0.24-1.07,0.08)$ & 0 \\
\hline & Radical cystectomy timing & $>3$ months & 1 & $0.45(0.12-1.64,0.23)$ & not available \\
\hline & & $<3$ months & 2 & $0.54(0.22-1.34,0.18)$ & 0 \\
\hline \multirow[t]{5}{*}{$5-y r$} & All included studies & & 4 & $1.17(0.75-1.82,0.49)$ & 46 \\
\hline & Radical cystectomy timing & $>3$ months & 1 & $0.38(0.11-1.32,0.13)$ & not available \\
\hline & & $<3$ months & 3 & $1.37(0.85-2.21,0.2)$ & 0 \\
\hline & Age & $<65$ years old & 3 & $1.03(0.40-2.63,0.95)$ & 58 \\
\hline & & $>65$ years old & 1 & $0.83(0.33-2.06,0.69)$ & not available \\
\hline \multirow[t]{5}{*}{$10-y r$} & All included studies & & 3 & $0.80(0.30-2.14,0.66)$ & 54 \\
\hline & Radical cystectomy timing & $>3$ months & 1 & $0.28(0.08-0.98,0.05)$ & not available \\
\hline & & $<3$ months & 2 & $1.31(0.62-2.76,0.48)$ & 0 \\
\hline & Age & $<65$ years old & 2 & $0.56(0.14-2.26,0.41)$ & 56 \\
\hline & & $>65$ years old & 1 & $1.36(0.56-3.33,0.49)$ & not available \\
\hline $15-y r$ & All included studies & & 2 & $1.07(0.08-13.68,0.96)$ & 91 \\
\hline
\end{tabular}



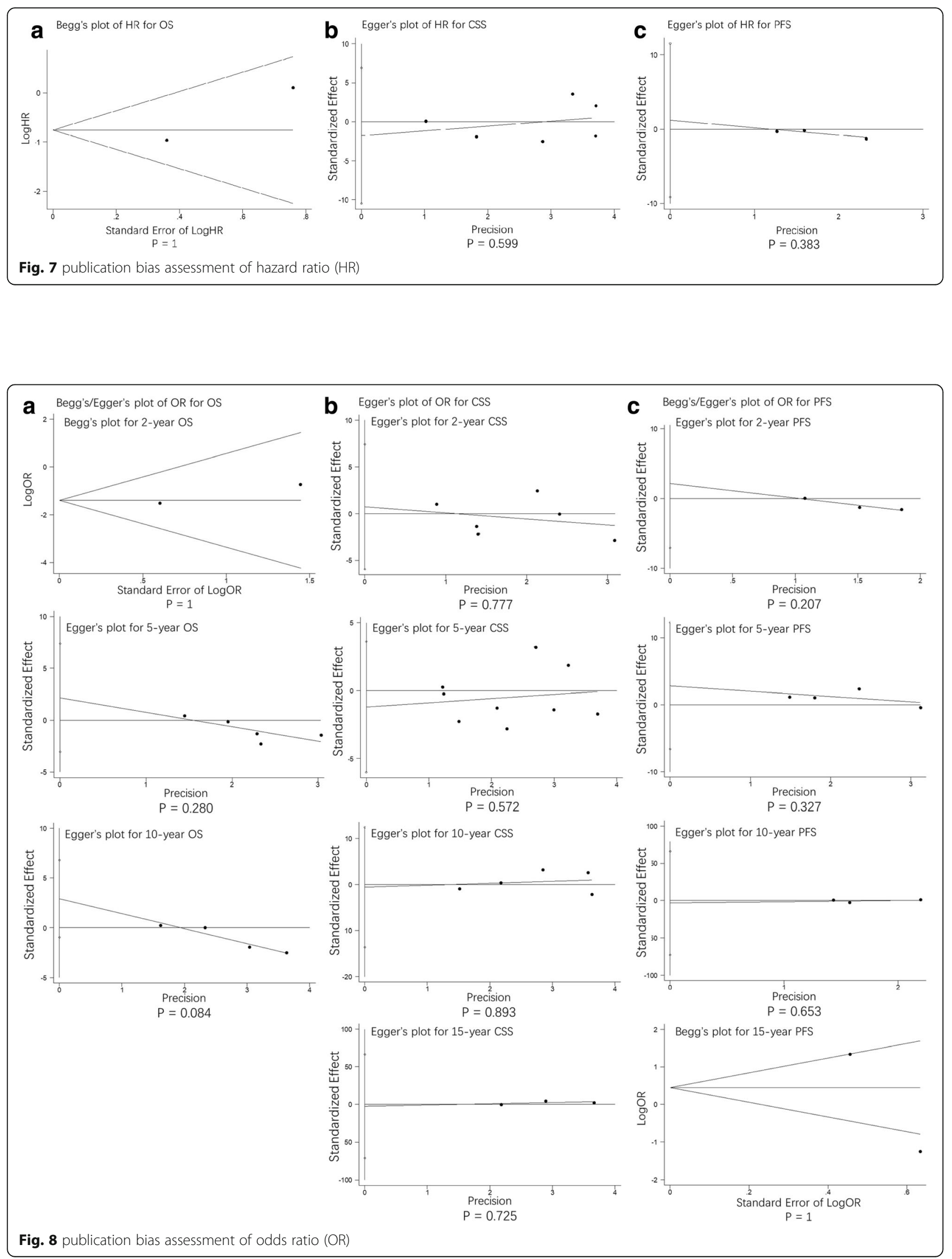
high-risk recurrence and progression [13]. Early detection following early treatment will lead to better survival outcome.

Several significant heterogeneities were observed which could be explained by the differences among studies such as study size, timing of radical cystectomy, bladder preservation modality, and follow-up time. Generally, a larger sample size or longer follow-up time represented a more stable outcome. Among the included studies, heterogeneity could be a result of radical cystectomy performed within or more than 3 months after diagnosis and bladder preservation modality, which varied from study to study. Characteristics of tumor (unifocal or multifocal, size, and grade) and patients (race, age, gender, and risk classification) could also contribute to the heterogeneity results. Multifocal, larger size, and higher grade result in a greater likelihood of a malignant behavior. Differences in race, age, gender, and risk classification may also cause a difference in disease feature and therapeutic responsiveness. Older patients and high-risk tumors usually have the worse prognosis. In addition, the difference in skill level of physician and pathologist will strongly affect the diagnosis and treatment and needs to be considered as an influencing factor.

There were several limitations to our analysis. First, no randomized control trials were found during our searching process probably because of ethical reasons; hence, only included retrospective cohort studies were used for our analysis. Second, differences among eligible studies were inevitable. We selected studies conducted worldwide; hence, the race of the patients were variable. Multiple therapeutic agents and management schedules were used in the BP group. In addition, the observation was included which may cause the BP effect to vary from study to study. Additionally, the use of either the 1973 WHO grading system or 2004 revision may have affected the results of our meta-analysis. Third, as outlined by the NOS scale, some of the included studies failed to control additional factors for comparability, had a short-term follow-up, or did not describe the followup schedule and hence contributed to the bias of the studies. Fourth, due to missing or lack of data, some analyses were performed on limited studies, and several subgroup analysis were unable to be performed. Fifth, disease recurrence is a very important outcome but no study provided such data for analysis.

\section{Conclusion}

From our meta-analysis, we concluded that although having the same effect of preventing cancer-specific death and progression from HGNMIBC, bladder preservation approach is a superior modality compared to radical cystectomy. It provides better overall survival outcome, especially for the elderly and patients with
T1G3 tumor. However, choosing an optimal BP strategy is still unclear and indefinite. For patients with expected longer life expectancy, RC could be a better option (more specifically, RC performed more than 3 months from diagnosis). However, this conclusion is from very limited data, which needs to be verified using future studies. During the decision-making process of selecting a treatment modality, quality of life should be considered equal to survival outcome. Last but not the least, a close follow-up is essential for any treatment modality.

Heterogeneity and limitations were inevitable and decreased the reliability of our study. Hence, a high quality, prospective, randomized study comparing the effectiveness and the tolerability of $\mathrm{BP}$ versus $\mathrm{RC}$ is extremely necessary in the future. There are protocols for randomized controlled feasibility studies designed to compare intravesical BCG and RC for high-risk non-muscleinvasive bladder cancer [62]. With the development of multiple BP modalities and reducing surgery, associated death rate will help develop an excellent curative effect and quality of life.

\section{Abbreviations \\ AJCC: American Joint Committee on Cancer; AUA: American Urological Association; BC: Bladder cancer; BCG: Bacillus Calmette-Guerin; BP: Bladder preservation; Cl: Confidence interval; CIS: Carcinoma in situ; CNKI: China National Knowledge Infrastructure; CSS: Cancer-specific survival; cT1: Clinical T1; cTa: Clinical Ta; CTC: Circulating tumor cells; EAU: European Association of Urology; EPI: Epirubicin; G1: Grade 1; G2: Grade 2; G3: Grade 3; HCPT: Hydroxycamptothecine; HG: High-grade; HGNMIBC: High-grade non-muscle-invasive bladder cancer; HR: Hazard ratio; IVT: Intravesical therapy; LG: Low-grade; MMC: Mitomycin; mo: Month; NCCN: National Comprehensive Cancer Network; NMIBC: Non-muscle-invasive bladder cancer; NOS: Newcastle-Ottawa Scale; OR: Odds ratio; OS: Overall survival; PFS: Progression-free survival; QoL: Quality of life; RC: Radical cystectomy; T1: Tumor invades lamina propria; Ta: Noninvasive papillary carcinoma; TNM: Tumor node metastases; TUR: Transurethral resection; un: Unknown; WHO: World Health Organization; yr: Year}

\section{Funding}

This work was supported by the Guangdong Medical Research Foundation (A2018103), Shantou Science and Technology Fund (2017026), and Guangdong Natural Science Fund Project (No. 2015A030310078).

\section{Availability of data and materials}

All data generated or analyzed during this study are included in this published article and reference articles.

\section{Authors' contributions}

PL and XJ designed this study. PL and YK completed the search and selection of articles. PL and ME extracted and analyzed the data. PL and ME wrote the manuscript under the instruction of XJ. All authors read and approved the final manuscript.

Ethics approval and consent to participate Not applicable.

Consent for publication

Not applicable.

Competing interests

The authors declare that they have no competing interests. 


\section{Publisher's Note}

Springer Nature remains neutral with regard to jurisdictional claims in published maps and institutional affiliations.

\section{Author details}

'Department of Urology, The First Affiliated Hospital of Shantou University Medical College, No. 57, Changping Road, Jinping District, Shantou, Guangdong, China. ${ }^{2}$ Shantou University Medical College, No. 22, Xinling Road, Jinping District, Shantou, Guangdong, China.

\section{Received: 13 July 2018 Accepted: 20 September 2018} Published online: 02 October 2018

\section{References}

1. Stewart B, Wild C: World cancer report 2014. International Agency for Research on Cancer; 2014.

2. Charlson FJ, Erskine HE, Ferrari AJ, Leung J, Whiteford HA, Abajobir AA Knibbs LD, Lalloo R, Scott JG, Guo Y: Global, regional, and national incidence, prevalence, and years lived with disability for 310 diseases and injuries, 1990-2015: a systematic analysis for the Global Burden of Disease Study 2015. 2016.

3. Cancer Stat Facts: Bladder Cancer https://seer.cancer.gov/statfacts/html/ urinb.html. Accessed 2 June 2018.

4. Aldousari S, Kassouf W. Update on the management of non-muscle invasive bladder cancer. Canadian Urol Assoc j. 2010;4:56-64.

5. Edge S, Byrd D, Compton C, Fritz A, Greene F. AJCC cancer staging handbook. 7th ed; 2010

6. Mostofi FK, Davis CJ, Sesterhenn IA, Sobin LH. Histological Typing of Urinary Bladder Tumours. Springer Berlin Heidelberg; 1999.

7. Eble JN, Sauter G, Epstein JI, Sesterhenn IAE. World Health Organization Classification of Tumours. Pathology and Genetics of Tumours of the Urinary System and Male Genital Organs. Lyon, France: IARC Press; 2004. p. 89-158.

8. van Rhijn BW, van Leenders GJ, Ooms BC, Kirkels WJ, Zlotta AR, Boevé ER, Jöbsis AC, Th VDK. The pathologist's mean grade is constant and individualizes the prognostic value of bladder cancer grading. Eur Urol. 2010;57:1052-7.

9. May M, Brookman-Amissah S, Roigas J, Hartmann A, Storkel S, Kristiansen G, Gilfrich C, Borchardt R, Hoschke B, Kaufmann O, Gunia S. Prognostic accuracy of individual uropathologists in noninvasive urinary bladder carcinoma: a multicentre study comparing the 1973 and 2004 World Health Organisation classifications. Eur Urol. 2010;57:850-8.

10. Otto W, Denzinger S, Fritsche HM, Burger M, Wieland WF, Hofstädter F, Hartmann A, Bertz S. The WHO classification of 1973 is more suitable than the WHO classification of 2004 for predicting survival in pT1 urothelial bladder cancer. BJU Int. 2011;107:404-8.

11. Soloway MS. It is time to abandon the "superficial" in bladder cancer. Eur Urol. 2007;52:1564-5.

12. Kulkarni GS, Hakenberg OJ. An updated critical analysis of the treatment strategy for newly diagnosed high-grade $\mathrm{T1}$ (previously $\mathrm{T1G}$ ) bladder cancer. Eur Urol. 2010;57:60-70

13. Cookson MS, Herr HWZhang ZF, Soloway S, Sogani PC, Fair WR. The treated natural history of high risk superficial bladder cancer: 15-year outcome. J Urol. 1997;158:62-7.

14. Lamm DL, Thor DE, Harris SC, Reyna JA, Stogdill VD, Radwin HM. Bacillus Calmette-Guerin immunotherapy of superficial bladder cancer. J Urol. 1980; 124:38-40.

15. Pinsky C, Camacho F, Kerr D, Braun D, Whitmore W, Oettgen H: Treatment of superficial bladder cancer with intravesical BCG. 1983.

16. Herr HW, Morales A. History of bacillus Calmette-Guerin and bladder cancer: an immunotherapy success story. J Urol. 2008;179:53-6.

17. Chang SS, Cookson MS. Non-muscle-invasive bladder cancer: the role of radical cystectomy. Urology. 2005;66:917-22.

18. Soloway MS, Sofer M, Vaidya A. Contemporary management of stage T1 transitional cell carcinoma of the bladder. J Urol. 2002:167:1573-83.

19. $M B$ HL, R H HK. Recurrence and progression of stage $T 1$, grade 3 transitional cell carcinoma of the bladder following intravesical immunotherapy with bacillus Calmette-Guerin. J Urol. 2000;163:1697-701.

20. Pansadoro V, Emiliozzi P. Defidio L, Donadio D, Florio A, Maurelli S, Lauretti S, Sternberg CN. Bacillus Calmette-Guerin in the treatment of stage T1 grade 3 transitional cell carcinoma of the bladder: long-term results. J Urol. 1995;154:2054-8.
21. Woldu SL, Şanli Ö, Lotan Y. Tackling non-muscle invasive bladder cancer in the clinic. Expert Rev Anti-Infect Ther. 2017:17(5):467-80.

22. Shahin O, Thalmann GN, Rentsch C, Mazzucchelli L, Studer UE. A retrospective analysis of 153 patients treated with or without intravesical bacillus Calmette-Guerin for primary stage $\mathrm{T} 1$ grade 3 bladder cancer: recurrence, progression and survival. J Urol. 2003:169:96-100.

23. Wiesner C, Pfitzenmaier J, Faldum A, Gillitzer R, Melchior SW, Thüroff JW Lymph node metastases in non-muscle invasive bladder cancer are correlated with the number of transurethral resections and tumour upstaging at radical cystectomy. British Journal of Urology International. 2015;95:301-5

24. van den Bosch S, Alfred Witjes J. Long-term cancer-specific survival in patients with high-risk, non-muscle-invasive bladder cancer and tumour progression: a systematic review. Eur Urol. 2011;60:493-500.

25. Stein JP, Penson DF. Invasive T1 bladder cancer: indications and rationale for radical cystectomy. BJU Int. 2010;102:270-5

26. Shabsigh A, Korets R, Vora KC, Brooks CM, Cronin AM, Savage C, Raj G Bochner BH, Dalbagni G, Herr HW. Defining early morbidity of radical cystectomy for patients with bladder cancer using a standardized reporting methodology. Eur Urol. 2009;55:164-76.

27. Hautmann RE, Volkmer BG, Gust K. Quantification of the survival benefit of early versus deferred cystectomy in high-risk non-muscle invasive bladder cancer (T1 G3). World J Urol. 2009;27:347-51.

28. Jäger W, Thomas C, Haag S, Hampel C, Salzer A, Thüroff JW, Wiesner C. Early vs delayed radical cystectomy for 'high-risk' carcinoma not invading bladder muscle: delay of cystectomy reduces cancer-specific survival. BJU Int. 2011; 108:E284-8.

29. Thalmann GN, Markwalder R, Shahin O, Burkhard FC, Hochreiter WW, Studer UE. Primary $\mathrm{T} 1 \mathrm{G} 3$ bladder cancer: organ preserving approach or immediate cystectomy? J Urol. 2004;172:70-5.

30. Stöckle M, Alken P, Engelmann U, Jacobi GH, Riedmiller $H$, Hohenfellner $R$. Radical cystectomy - often too late? Eur Urol. 1987;13:361.

31. Hardt J, Egle UT. Quality of life in patients with bladder carcinoma after cystectomy: first results of a prospective study. Quality of Life Research An International Journal of Quality of Life Aspects of Treatment Care \& Rehabilitation. 2000:9:1-12

32. Chang SS, Boorjian SA, Chou R, Clark PE, Daneshmand S, Konety BR, Pruthi R, Quale DZ, Ritch CR, Seigne JD, et al. Diagnosis and treatment of non-muscle invasive bladder cancer: AUA/SUO guideline. J Urol. 2016;196:1021-9.

33. Babjuk M, Burger M, Compérat E, Gontero P, Mostafid H, Palou J, van Rhijn B, Rouprêt M, Shariat S, Sylvester R, et al: EAU guidelines on non-muscleinvasive bladder cancer(TaT1 and CIS). 2017.

34. NCCN Guidelines Version 3. 2018 Bladder Cancer https://www.nccn.org/ professionals/physician_gls/pdf/bladder.pdf. Accessed 20 June 2018.

35. Kulkarni GS, Finelli A, Fleshner NE, Jewett MA, Lopushinsky SR, Alibhai SM Optimal management of high-risk T1G3 bladder cancer: a decision analysis. PLoS Med. 2007:4:e284.

36. Daneshmand S. Determining the role of cystectomy for high-grade T urothelial carcinoma. Urol Clin N Am. 2013:40:233-47.

37. Maclennan GT, Kirkali Z, Cheng L. Histologic grading of noninvasive papillary urothelial neoplasms. Eur Urol. 2007:51:889-98.

38. Wells GA, Shea BJ, O'Connell D, Peterson J, Welch V, Losos M, Tugwell P. The Newcastle-Ottawa Scale (NOS) for assessing the quality of nonrandomized studies in meta-analysis. Applied Engineering in Agriculture. 2014;18:727-34.

39. De Berardinis E, Busetto GM, Antonini G, Giovannone R, Gentile V. T1G3 high-risk NMIBC (non-muscle invasive bladder cancer): conservative treatment versus immediate cystectomy. Int Urol Nephrol. 2011;43:1047-57.

40. Denzinger S, Burger M, Fritsche HM, Ganzer R, Blana A, Wieland WF, Otto W. Bladder preservation or initial cystectomy in T1G3 bladder cancer: which parameters help in therapeutic decision-making? Aktuelle Urologie. 2008;39:58-61.

41. Ming-hui LI, Wei-bing SUN: Primary T1G3 bladder cancer TURBT+BCG or immediate cystectomy. 2011.

42. Patard JJ, Moudouni S, Saint F, Rioux-Leclercq N, Manunta A, Guy L, Ballanger $\mathrm{P}$, Lanson $\mathrm{Y}$, Haji $\mathrm{M}$, Irani J, et al. Tumor progression and survival in patients with T1G3 bladder tumors: multicentric retrospective study comparing 94 patients treated during 17 years. Urology. 2001;58:551-6.

43. Xiao-wen SUN, Ming-shan Y, Dong-bin BI, Wei-guo LI, Hai-tao LIU, Bang-min HAN. Management of primary T1G3 bladder cancer:immediate cystectomy or bladder preserving approach? Chin J Urol. 2008;29:811. 
44. Spaliviero M, Dalbagni G, Bochner BH, Poon BY, Huang H, Al-Ahmadie HA, Donahue TF, Taylor JM, Meeks JJ, Sjoberg DD, et al. Clinical outcome of patients with $\mathrm{T1}$ micropapillary urothelial carcinoma of the bladder. J Urol. 2014;192:702-7.

45. Wong SW, Durkan GC. Immediate versus delayed cystectomy for high-grade PT1 transitional cell carcinoma of the bladder. BJU Int. 2009;103:4

46. Badalato GM, Gaya JM, Hruby G, Patel T, Kates M, Sadeghi N, Benson MC, McKiernan JM. Immediate radical cystectomy vs conservative management for high grade cT1 bladder cancer: is there a survival difference? BJU Int. 2012;110:1471-7.

47. A M DE, AW B. Intracavitary Bacillus Calmette-Guerin in the treatment of superficial bladder tumors. J Urol. 1976;167:891-4.

48. Dinney CP, Babkowski RC, Antelo M, Perrotte P, Liebert M, Zhang HZ, Palmer J, Veltri RW, Katz RL, Grossman HB. Relationship among cystectomy, microvessel density and prognosis in stage $\mathrm{T} 1$ transitional cell carcinoma of the bladder. J Urol. 1998;160:1285-90.

49. Stein JP, Lieskovsky G, Cote R, Groshen S, Feng AC, Boyd S, Skinner E, Bochner B, Thangathurai D, Mikhail M. Radical cystectomy in the treatment of invasive bladder cancer: long-term results in 1,054 patients. J Clin Oncol. 2001:19:666-75.

50. Malmström PU, Sylvester RJ, Crawford DE, Friedrich M, Krege S, Rintala E, Solsona E, Di SS, Witjes JA. An individual patient data meta-analysis of the long-term outcome of randomised studies comparing intravesical mitomycin C versus bacillus Calmette-Guerin for non-muscle-invasive bladder cancer. Eur Urol. 2009;56:247-56.

51. Sylvester RJ, Brausi MA, Kirkels WJ, Hoeltl W, Calais Da Silva F, Powell PH, Prescott S, Kirkali Z, van de Beek C, Gorlia T, de Reijke TM. Long-term efficacy results of EORTC genito-urinary group randomized phase 3 study 30911 comparing intravesical instillations of epirubicin, bacillus CalmetteGuerin, and bacillus Calmette-Guerin plus isoniazid in patients with intermediate- and high-risk stage Ta T1 urothelial carcinoma of the bladder. Eur Urol. 2010;57:766-73.

52. Duchek M, Johansson R, Jahnson S, Mestad O, Hellström P. Hellsten S, Malmström PU. Bacillus Calmette-Guérin is superior to a combination of epirubicin and interferon-alpha2 $b$ in the intravesical treatment of patients with stage $\mathrm{T} 1$ urinary bladder cancer. A prospective, randomized, Nordic study. Eur Urol. 2010;57:25-31.

53. Järvinen R, Kaasinen E, Sankila A, Rintala E. Long-term efficacy of maintenance bacillus Calmette-Guerin versus maintenance mitomycin $C$ instillation therapy in frequently recurrent TaT1 tumours without carcinoma in situ: a subgroup analysis of the prospective, randomised FinnBladder I study with a 20. Eur Urol. 2009:35:260-5.

54. Martin-Doyle W, Leow JJ, Orsola A, Chang SL, Bellmunt J. Improving selection criteria for early cystectomy in high-grade t1 bladder cancer: a meta-analysis of 15,215 patients. J Clin Oncol. 2015;33:643-50.

55. Hurle R, Buffi N, Lista G, Cardone P, Forni G, Maffei D, Peschechera R Zandegiacomo S, Pasini L, Benetti A, et al: Long-term outcomes of high grade $\mathrm{T} 1$ bladder cancer treated with intravesical Bacille Calmette-Guerin therapy: a single-institutional experience. 2018.

56. May M, Helke C, Nitzke T, Vogler H, Hoschke B. Survival rates after radical cystectomy according to tumor stage of bladder carcinoma at first presentation. Urol Int. 2004;72:103-11.

57. Matsuda T, Aptel I, Exbrayat C, Grosclaude P. Determinants of quality of life of bladder cancer survivors five years after treatment in France. Int J Urol. 2010;10:423-9

58. Modh RA, Mulhall JP, Gilbert SM. Sexual dysfunction after cystectomy and urinary diversion. Nature Reviews Urology. 2014;11:445-53.

59. Smith ZL, Johnson SC, Golan S, McGinnis JR, Steinberg GD, Smith ND. Fistulous complications following radical cystectomy for bladder cancer: analysis of a large modern cohort. J Urol. 2018;199(3):663-8.

60. Castillo OA, Campos Juanatey F, Vives Rivera F, Lopez-Vallejo J. Fistula between external iliac artery and ileal conduit after radical cystectomy: a life-threatening complication. Arch Esp Urol. 2013;66:967-9.

61. Saluja M, Gilling P. Intravesical bacillus Calmette-Guérin instillation in nonmuscle-invasive bladder cancer: a review. Int J Urol. 2018; 25(1):18-24.

62. Oughton JB, Poad H, Twiddy M, Collinson M, Hiley V, Gordon K, Johnson M, Jain S, Noon AP, Chahal R, et al. Radical cystectomy (bladder removal) against intravesical BCG immunotherapy for high-risk non-muscle invasive bladder cancer (BRAVO): a protocol for a randomised controlled feasibility study. BMJ Open. 2017;7:e017913.

Ready to submit your research? Choose BMC and benefit from:

- fast, convenient online submission

- thorough peer review by experienced researchers in your field

- rapid publication on acceptance

- support for research data, including large and complex data types

- gold Open Access which fosters wider collaboration and increased citations

- maximum visibility for your research: over $100 \mathrm{M}$ website views per year

At $\mathrm{BMC}$, research is always in progress.

Learn more biomedcentral.com/submissions 